\title{
Effectiveness Study of English Learning in Blended Learning Environment
}

\author{
Wenyu Liu \\ School of Foreign Languages, Dalian University of Technology, Dalian, China \\ Email: wenyulaoshi@gmail.com \\ Hanjing Yu \\ School of Foreign Languages, Dalian University of Technology, Dalian, China \\ Email: yuhanj823@126.com
}

\begin{abstract}
The wide application of information technology makes web-based instruction pervasive in all levels of China's educational institutions. The study aims to explore the inner relationship between learning motivations and learning strategies in the blended EFL learning environments based on a review on former studies about learning motivations, learning strategies and self-regulated learning. Altogether 540 pieces of questionnaire were distributed to non-English majored students in Dalian University of Technology who learnt English in a blended environment. Using the software SPSS, the data were thoroughly analyzed, indicating that students who display more adaptive self-regulatory strategies demonstrate better learning efficacy and higher motivation for learning and students' performance is predictable with the help of learning motivation and strategies.
\end{abstract}

Index Terms - blended learning environment, learning motivation, learning strategy, MSLQ, SPSS

\section{INTRODUCTION}

The fast development of information technology makes web-based instruction pervasive. In Chinese higher education institutions, English is still a compulsory core course from undergraduates to doctoral students. To continuously improve the English teaching and learning effectiveness and efficiency, some Chinese universities have developed web-based instruction systems for EFL and teaching.

Postgraduate English teaching in Dalian University of Technology (DUT) is confronted with the challenge of implementing individualized instruction and constructing autonomous learning environment due to the increase of student enrollment, Therefore, DUT developed the Self-Access English Learning System for the non-English-major postgraduates. Since spring 2005, the Self Access English Learning System has been applied as a supplement to classroom instruction, establishing an effective blended learning environment to facilitate postgraduate students' English learning in DUT.

Studies on second language (L2) acquisition have reported that different students with different learning motivations usually tend to select different strategies (Liu \& Cha, 2009; Liu \& Cha, 2010). In addition, some scholars have also pointed out that learning motivations and strategies strongly affect students' English learning (Zimmerman \& Schunk, 2001; Pintrich, 2000, 2003). Considering the practical implications for the research involving substantial learning environments, the authors conducted the current study based on the theories on motivations and strategies developed by Pintrich and Schunk etc. Their theories, from a social cognitive view, argue that learning motivations and strategies consist of three components and each component includes several more specific items. On the solid foundation of the above mentioned theories about learning motivations and strategies, the inner relationship between motivations and strategy components can be investigated into and pedagogical implications to improve current English teaching environment may be found as well. Therefore, the study attempts to analyze the collected data about students' English learning efficacy and efficiency in the blended environment, in the hope of finding possible method to predict students' performance in blended learning environment.

\section{LITERATURE REVIEW}

\section{A. Blended Learning Environment}

Though commonly applied in higher education, blended learning does not have a universally accepted definition, either abroad or at home (different definitions see Bersin \& Howard, 2004; Garrison \& Kanuka, 2004; Harriman, 2004; Singh, 2003). Based on the definitions proposed by some scholars, especially that by Dr. Driscoll (2002), here in this paper, blended learning is referred to as a blending of different learning environments, or as a blending of methods, techniques or resources and applying them in an interactively meaningful learning environment. 
In such a blended learning environment, learners should have easy access to different learning resources in order to apply the knowledge and skills they learn under the supervision and support of the teacher both inside and outside the classroom. Learners and teachers work together to improve the quality of learning and teaching, and the ultimate aim of blended learning is to provide practical opportunities for learners and teachers to make learning independent, useful, sustainable and ever growing. (Graham, 2005; Liu \& Cha, 2010)

The Self-Access English Learning System of DUT has made blended teaching and learning model possible, giving priority to students and stressing student's initiative. Meanwhile, there is also classroom teaching at fixed time in such a learning environment, where teachers can explain the mistakes and errors made by students and then accordingly offer appropriate learning strategies and techniques. Thus, students can get feedbacks in time, improving learning efficiency and efficacy more effectively.

\section{B. Learning Motivations and Learning Strategies}

Numerous studies have repeatedly shown a relationship between different variables of motivation orientation and academic achievement (Valentine, DuBois, \& Cooper, 2004; Nota, Soresi, \& Zimmerman, 2004). According to Nota, Soresi and Zimmerman (2004), the motivational self-regulation strategy is a significant predictor of the students' high school diploma grades and their desire to pursue further education after high school.

\section{Learning Motivation and Self-regulated Learning}

Motivations in L2 learning have, indeed, chiefly been used to refer to the long-term fairly stable attitudes in the students' minds. Two types of favorable motivation, namely integrated and instrumental motivation, have been introduced by Gardner and Lambert $(1972,1985)$. The integrated motivations reflect whether the student identifies with the target culture and people, or rejects them. The more that a student admires the target culture, the more successful the student will be in the L2 classroom. The instrumental motivations mean learning the language for an ulterior motive unrelated to the use by its native speakers - to pass an examination, to get a certain kind of job, and so on. L2 motivation should not therefore be considered as a forced choice between these two. Both types are important. A student might learn an L2 well with an integrative motivation or with an instrumental one, or indeed with both, for one does not rule out the other.

With the development of motivation theory, other approaches to the study of motivation have emerged. Recently, researchers have taken a primarily social cognitive approach to the study of motivation, with an emphasis on the role of students' beliefs and strategies (Nota, Soresi, \& Zimmerman, 2004). Theorists have largely conceptualized motivation as a process, rather than a product. It is believed that motivation can be discerned through students' reports of their beliefs as well as through behaviors such as choice of activities, level and quality of task engagement, persistence, and performance. Consequently, self-regulated learning, from the social cognitive perspective, has been developed and research elaborately by several scholars, among whom Pintrich and Schunk, etc. are the most recognized, with a large number of paper and books published elaborating on this topic.

One of the major contributions Pintrich has made to the field of self-regulated learning is the conceptual framework he formulated. Pintrich $(2000,2002)$ argues that self-regulatory activities mediate the relations between learners and their environments and influence learners' achievements. According to Pintrich, self-regulation comprises four phases, namely, a) forethought, planning and activation, b) monitoring, c) control, and d) reaction and reflection. In addition, four possible areas, i.e. cognition, motivation/affect, behavior and context are critical to self-regulation in each phase.

This model specifies the possible range of activities and does not necessitate them. The full range of areas may not be amenable to self-regulation, and within any area some activities may require little if any self-regulation. The model does not presume that the phases are linearly ordered; instead, they may occur at any time during task engagement. There are learning situations in which learners may engage in some but not all of the phases. Phases also are interactive in that individuals may simultaneously engage in more than one.

\section{Learning Strategy and Self-regulated Learning}

A central research project on learning strategies is the comprehensive research program by O'Malley and Chamot (1990), who define learning strategy as the 'the special thoughts or behavior' that individuals use to help them comprehend, learn, or retain new information. They further divide learning strategy into three subcomponents, i.e. meta-cognitive strategies, cognitive strategies, and social mediation strategies.

\section{a. Meta-cognitive Strategies}

Meta-cognitive strategies 'are higher order executive skills that may entail planning for, monitoring or evaluating the success of a learning activity' (O’ Malley \& Chamot, 1990). In other words, they are strategies about learning rather than learning strategies themselves.

b. Cognitive Strategies

Cognitive strategies 'operate directly on incoming information, manipulating it in ways that enhance learning' (O' Malley \& Chamot, 1990).

c. Social Mediation Strategies

Social mediation strategies, or social/affective strategies, 'represent a broad grouping that involves either interaction with another person or ideational control over affect'. (O' Malley et al., 1985) 
Meanwhile, from a more specific point of view, Pintrich \& DeGroot (1990) suggest that positive motivations could promote some more deliberate learning strategies, including cognitive strategies, self-regulated strategies and management strategies.

\section{d. Cognitive learning strategies}

In terms of cognitive learning strategies, following the work of Weinstein and Mayer (1986), rehearsal, elaboration and organizational strategies are identified as important cognitive strategies related to academic performance in the classroom. These strategies can be applied to simple memory tasks (e.g., recall of information, words, or lists) or to more complex tasks that require comprehension of the information (e.g., understanding a piece of text or a lecture).

e. Meta-cognitive and self-regulatory strategies

Apart from cognitive strategies, students' meta-cognitive knowledge and use of meta-cognitive strategies can have an important influence upon their achievement. There are two general aspects of meta-cognition, namely, knowledge about cognition and self-regulation of cognition. Some scholars have suggested that meta-cognitive knowledge has been limited to students' knowledge about person, task, and strategy variables. Self-regulation would then refer to students' monitoring, controlling, and regulating their own cognitive activities and actual behavior.

\section{f. Resource management strategies}

The final component of our model of learning and self-regulatory strategies, resource management strategies, concerns strategies that students use to manage and control their environment. Examples include managing and controlling their time, effort, study environment, and other people (including teachers and peers), through the use of help-seeking strategies. In line with a general adaptive approach to learning, these resource management strategies are assumed to help students adapt to their environment.

\section{RESEARCH DESIGN}

\section{A. Subjects}

In the pretest which was designed to verify the validity of the questionnaire adopted in this study, 200 students participated and submitted the results. In the formal test afterwards, the questionnaires were distributed to altogether 700 students across three educational levels from Dalian University of Technology (DUT), and at last, 340 were collected, including 120 pieces of questionnaire by non-English major undergraduate students, 120 pieces by non-English major post-graduate students and 100 pieces by non-English major doctoral students. Most of the subjects had experience of using the self-access English learning system, which is one of the most important learning environments in this study, and immersed in classroom-based English teaching environment. Considering the imbalance of gender distribution on the whole campus of DUT, it is reasonable that the majority of the subjects in this research are male students, accounting for about $60 \%$.

\section{B. Instrument}

The Questionnaire adopted in this research, based on research of Pintrich et al., is the Chinese version of Motivated Strategies for Learning Questionnaire Manual, also MSLQ, in which the validity and reliability are guaranteed. The Chinese version was chosen since it is convenient for subjects to read.

There are essentially two sections in the questionnaire, namely, a motivation section and a learning strategies section. The motivation section consists of 31 items that assess students' goal and value beliefs for a course, their beliefs about their skill to succeed in a course, and their anxiety about tests in a course. The learning strategy section includes 31 items regarding students' use of different cognitive and meta-cognitive strategies. In addition, the learning strategies section has 19 items concerning students' management of different resources. Most importantly, the Cronbach's alphas are robust, ranging from 0.52 to 0.93 with nearly 0.7 for most of items, which means the scales have good internal reliability.

Students rated themselves on a seven point Likert scale form "not at all true of me" to "very true of me". Scores were calculated by taking the mean of the items that make up that scale. Some items in the questionnaire were "reversed" coded and must be reversed when computing the scores. To make it more specifically, a person who chose 1 for a reversed item got a score of 7 for that item. Accordingly, 2 became 6, and 3 became 5, 4 remained 4, 5 became 3, 6 became 2, and 7 became 1 . All data were analyzed and processed with the help of the software Statistical Package for the Social Science, or SPSS.

\section{RESUlts AND FINDINGS}

\section{A. Correlation between Learning Motivation and Learning Strategies}

When using SPSS to explore the data, it was found that no variables for learning motivations and strategies could meet the requirement of normality, so here Spearman Rank Correlation was employed instead of Pearson Parametric Correlation. Results are displayed in Table 1. 
TABLE 1.

SPEARMEN CORRELATION OF LEARNING MOTIVATION AND STRATEGIES

\begin{tabular}{|c|c|c|c|c|c|c|}
\hline Variable & Intrinsic goal & Extrinsic goal & Task value & Belief & Self-efficacy & Anxiety \\
\hline \multirow{2}{*}{ Rehearsal } & $.463(* *)$ & $.303(* *)$ & $.433(* *)$ & $.198(* *)$ & $.394(* *)$ & $.144(* *)$ \\
\hline & .000 & .000 & .000 & .000 & .000 & .008 \\
\hline Elaboration & $.528(* *)$ & $.206(* *)$ & $.532(* *)$ & $.373(* *)$ & $.597(* *)$ & $-.183(* *)$ \\
\hline \multirow{2}{*}{ Organization } & $.412(* *)$ & $.300(* *)$ & $.395(* *)$ & $.170(* *)$ & $.457(* *)$ & $.131\left(^{*}\right)$ \\
\hline & .000 & .000 & .000 & .002 & .000 & .017 \\
\hline \multirow{2}{*}{$\begin{array}{l}\text { Meta-cognitive } \\
\text { Self-regulation }\end{array}$} & $.543(* *)$ & $.230(* *)$ & $.499(* *)$ & $.388(* *)$ & $.667(* *)$ & $-.147(* *)$ \\
\hline & .000 & .000 & .000 & .000 & .000 & .008 \\
\hline \multirow{2}{*}{$\begin{array}{l}\text { Time and study } \\
\text { environment }\end{array}$} & $.432(* *)$ & .002 & $.320(* *)$ & $.223(* *)$ & $.522(* *)$ & $-.328(* *)$ \\
\hline & .000 & .972 & .000 & .000 & .000 & .000 \\
\hline Effort regulating & $.217(* *)$ & $.147(* *)$ & $.200(* *)$ & $.178(* *)$ & $.397(* *)$ & $-.214(* *)$ \\
\hline Help seeking & .000 & .016 & .000 & .000 & .000 & .859 \\
\hline
\end{tabular}

The figures in table 1 indicate that correlation coefficient among most motivation orientations and learning strategies are valid, or significant in statistic (only except four pairs: critical thinking, time and study environment and extrinsic goal orientation, peer learning and control of learning beliefs, help seeking and test anxiety). Nevertheless, it is possible that small correlation coefficient could be significant in large-sampled survey, so it is necessary to sort out correlation coefficient big enough $(r \geq 0.5)$ putting to analysis, which accord with practical survey, for not each orientations would correlate to every learning strategies and students with different motivation orientations tend to make use of different learning strategies correspondingly. According to table 2, however, the correlation among affective component (test anxiety) and two learning strategies is too small to be significant.

TABLE 2.

SPEARMEN CORRELATION OF LEARNING MOTIVATION AND STRATEGIES COMPONENT

\begin{tabular}{|l|l|l|l|}
\hline \multirow{2}{*}{ Variable } & Value component & Expectancy component & $\begin{array}{l}\text { Affective } \\
\text { component }\end{array}$ \\
\hline \multirow{2}{*}{ Cognitive and meta-cognitive strategies } & $.552^{(* *)}$ & $.508\left(^{* *}\right)$ & -.007 \\
\cline { 2 - 4 } & .000 & .000 & .909 \\
\hline \multirow{2}{*}{ Meta-cognitive self-regulation } & $.389^{(* *)}$ & $.399\left(^{* *}\right)$ & -.046 \\
\cline { 2 - 4 } & .000 & .000 & .417 \\
\hline
\end{tabular}

Table 2 lists the integrated correlation coefficients among motivation components and learning strategies, which indicates that value component and expectancy component are closely correlated to cognitive and meta-cognitive strategies $(\mathrm{r}=0.552,0.508)$; while correlation among value and expectancy component and meta-cognitive self-regulation is comparatively weaker $(\mathrm{r}=0.3389,0.399)$. Moreover, correlation among affective component and the two learning strategy components is weak that correlation coefficients are even significant in statistics $(r=-0.007$, -0.046).

\section{B. Different Strategies between High-motivated and Low-motivated Groups}

Students on three levels were sorted out and classified into two groups, namely, the high-motivated group with $25 \%$ of highest motivation score and low-motivated group with another $25 \%$ of lowest motivation score according to the sequence of students' ascending score in motivation scale. In the study, high-motivated group, with average score of 5.11, includes 79 students; while low-motivated group, with average score of 4.31, includes another 79 students.

Table 3 shows that students in high-motivated group tend to use learning strategies more frequently than in low-motivated group $(\mathrm{M}=5.06,4.83$ vs. 3.89, 4.24). Students in high-motivated, however, prefer cognitive and meta-cognitive strategies to meta-cognitive self-regulation $(\mathrm{M}=5.06>4.83)$; whereas, students on the counterpart prefer meta-cognitive self-regulation more $(M=4.24>3.89)$. Most importantly, the difference between high-motivated and low-motivated groups is significant in statistics $(\mathrm{t}=-8.49,-0.59 ; \mathrm{p}<0.05)$.

TABLE 3.

T TEST IN STRATEGIES CHOOSING OF HIGH-MOTIVATED AND LOW-MOTIVATED GROUPS

\begin{tabular}{|c|c|c|c|c|c|c|c|}
\hline \multirow{2}{*}{$\frac{\text { Group }}{\text { Strategies }}$} & \multicolumn{2}{|c|}{ Low-motivated (79) } & \multicolumn{2}{|c|}{ High-motivated (79) } & \multirow{2}{*}{$\begin{array}{c}\text { Mean } \\
\text { difference }\end{array}$} & \multirow{2}{*}{$\mathrm{t}$} & \multirow{2}{*}{ Sig. } \\
\hline & $\mathrm{M}$ & S. D. & $\mathrm{M}$ & S. D. & & & \\
\hline Cognitive and meta-cognitive strategies & 3.89 & 0.87 & 5.06 & 0.79 & -1.17 & -8.46 & .000 \\
\hline Meta-cognitive self-regulation & 4.24 & 0.77 & 4.83 & 0.73 & -0.59 & -4.81 & .000 \\
\hline
\end{tabular}




\section{Regression Analysis and Prediction of Students'Performance}

Stepwise method was employed in the regression analysis, as it combined the advantages of Backward and Forward. In addition, too many variables might lead to the super-fitting of the regression equation, so here the average scores of motivation and strategies as a whole were calculated to get two comprehensive variables - motivations variable and strategies variable, which then were put into regression analysis. This data treatment was proved valid through the final results ( $80 \%$ variance of dependent variable could be explained by independent variables).

With above method, a regression equation could be generated in form as follows:

$y=a+b_{1} X_{1}+b_{2} X_{2}+e$

Where,

$\mathrm{Y}$ - the students' performance, also final exam or CET-4 scores;

$\mathrm{X} 1$ - the learning strategy variable;

$\mathrm{X} 2$ - the motivation variable;

$\mathrm{e}-$ the equation error;

a, b1, b2 - estimated constants;

In table 4 , model 1 (with motivation variable only) and 2 (with both motivation variable and strategy variable) have high multiple correlation coefficient $(\mathrm{R}=0.908,0.913)$, which the linear relation among student performance and learning motivation as well as learning strategies are very significant. Besides, model 1 could explain $82.4 \%$ variance of student performance $(\mathrm{R}$ Square $=0.824$ ); while model 2 could explain $83.4 \%$ ( $\mathrm{R}$ Square $=0.834$ ), so the regression equation generated are quiet reliable and valid. One thing to notice, the only strategy variable could explain most variance of student performance (83.4\% vs. 82.4\%), which means usage of learning strategies influences student performance most.

TABLE 4.

REGRESSION SUMMERY

\begin{tabular}{|c|c|c|c|c|c|c|c|c|c|}
\hline \multirow[b]{2}{*}{ Model } & \multirow[b]{2}{*}{$\mathrm{R}$} & \multirow[b]{2}{*}{$\begin{array}{l}\mathrm{R} \\
\text { square }\end{array}$} & \multirow[b]{2}{*}{$\begin{array}{l}\text { Adjusted R } \\
\text { square }\end{array}$} & \multirow[b]{2}{*}{$\begin{array}{l}\text { Std. error of } \\
\text { the estimate }\end{array}$} & \multicolumn{5}{|c|}{ Change statistics } \\
\hline & & & & & $\begin{array}{l}\text { R square } \\
\text { change }\end{array}$ & $\mathrm{F}$ change & df1 & df 2 & $\begin{array}{l}\text { Sig. F } \\
\text { change }\end{array}$ \\
\hline 1 & $.908^{\mathrm{a}}$ & .824 & .823 & .32921 & .824 & 1279.304 & 1 & 273 & .000 \\
\hline 2 & $.913^{b}$ & .834 & .833 & .32014 & .010 & 16.685 & 1 & 272 & .000 \\
\hline
\end{tabular}

b. Predictors: (Constant), scores of learning strategies, scores of learning motivation

The results of both model 1 and model 2 all reach the statistical significance $(\mathrm{p}<0.05)$. For model 2 could explain more variance, here model 2 is extracted as regression equation. Then it should be as follows:

Student performance $=0.987+0.921 \times$ learning strategies $-0.138 \times$ learning motivation

TABLE 5.

REGRESSION COEFFICIENTS a

\begin{tabular}{|c|c|c|c|c|c|c|c|c|}
\hline \multirow{2}{*}{\multicolumn{2}{|c|}{ Model }} & \multicolumn{2}{|c|}{$\begin{array}{l}\text { Unstandardized } \\
\text { coefficients }\end{array}$} & \multirow{2}{*}{$\begin{array}{l}\text { Standardized } \\
\text { coefficients } \\
\text { Beta }\end{array}$} & \multirow{3}{*}{$\begin{array}{l}\mathrm{t} \\
4.771 \\
\end{array}$} & \multirow{3}{*}{$\begin{array}{l}\text { Sig. } \\
.000\end{array}$} & \multicolumn{2}{|c|}{ Collinearity statistics } \\
\hline & & & Std. & & & & \multirow{2}{*}{$\begin{array}{l}\text { Tolerance } \\
1.000\end{array}$} & \multirow{2}{*}{ VIF } \\
\hline 1 & (Constant) & .541 & .113 & & & & & \\
\hline & Scores of learning strategies & .877 & .025 & .908 & 35.761 & .000 & & 1.000 \\
\hline \multirow[t]{3}{*}{2} & (Constant) & .987 & .155 & & 6.361 & .000 & & \\
\hline & Scores of learning strategies & .921 & .026 & .954 & 35.151 & .000 & .827 & 1.209 \\
\hline & Scores of learning motivation & -.138 & .034 & -.111 & -4.085 & .000 & .827 & 1.209 \\
\hline
\end{tabular}

a. Dependent variable: scores of students' courses

Applying above equation, predicted performance of 340 students was calculated through input of their motivation and strategies scores, and compared with their real performance - final examination scores to verify the regression equation through Paired-sample T test. After the validity verification, predicted performance of another 100 students as control group was calculated with the same method

TABLE 6.

PAIRED-SAMPLE T TEST OF 340 STUDENTS

\begin{tabular}{|c|c|c|c|c|c|c|c|c|}
\hline \multirow{3}{*}{ Pair 1} & \multicolumn{5}{|c|}{ Paired Differences } & \multirow{3}{*}{$\mathrm{t}$} & \multirow{3}{*}{ df } & \multirow{3}{*}{$\begin{array}{l}\text { Sig. } \\
\text { (2-tailed) }\end{array}$} \\
\hline & \multirow[t]{2}{*}{ Mean } & \multirow[t]{2}{*}{$\begin{array}{l}\text { Std. } \\
\text { Deviation }\end{array}$} & \multirow[t]{2}{*}{$\begin{array}{l}\text { Std. Error } \\
\text { Mean }\end{array}$} & \multicolumn{2}{|c|}{$\begin{array}{l}95 \% \text { Confidence } \\
\text { Interval of the } \\
\text { Difference }\end{array}$} & & & \\
\hline & & & & Lower & Upper & & & \\
\hline Predicated scores - Real scores & .219 & 2.455 & .134 & -.046 & .483 & 1.627 & 333 & .105 \\
\hline
\end{tabular}


TABLE 7.

PAIRED-SAMPLE T TEST OF 100 STUDENTS

\begin{tabular}{|c|c|c|c|c|c|c|c|c|}
\hline \multirow{3}{*}{ Pair 1} & \multicolumn{5}{|c|}{ Paired Differences } & \multirow{3}{*}{$\mathrm{t}$} & \multirow{3}{*}{$\mathrm{df}$} & \multirow{3}{*}{$\begin{array}{c}\text { Sig. } \\
\text { (2-tailed) }\end{array}$} \\
\hline & \multirow[t]{2}{*}{ Mean } & \multirow[t]{2}{*}{$\begin{array}{c}\text { Std. } \\
\text { deviation }\end{array}$} & \multirow[t]{2}{*}{$\begin{array}{l}\text { Std. } \\
\text { error } \\
\text { mean }\end{array}$} & \multicolumn{2}{|c|}{$\begin{array}{l}95 \% \text { confidence } \\
\text { interval of the } \\
\text { difference }\end{array}$} & & & \\
\hline & & & & Lower & Upper & & & \\
\hline $\begin{array}{l}\text { After blended learning } \\
\text { environment - before blended } \\
\text { learning environment }\end{array}$ & .150 & .794 & .048 & .056 & .244 & 3.133 & 274 & .002 \\
\hline
\end{tabular}

and compared with their actual CET-4 scores, and then Paired-sample T test was also employed to check out whether students in blended environment tended to performed better (as is shown in Table 6 and table 7).

Table 6 shows that the predicted performance is similar to the real score $(p=0.105)$, and the regression equation is valid. In table 7, however, it is proved that there did exist difference if students did not take course in blended learning environment $(\mathrm{p}=0.002)$.

\section{DISCUSSION}

This study employs the theories based on the work by Pintrich etc. and analyzes the data gathered through questionnaires for the Self Access English Learning System, with help of which the learning environment in DUT is assessed and the English learning situation of students on different levels is explored. The research results strongly prove that there is certain relationship between students' learning motivation and learning strategies; and the Self Access English Learning System can improve students' English learning effects as well as increase their final examination scores, to which extent the Self Access English Learning System is valid as proved from several numerical results.

First of all, the present study explores the correlation between students' motivation orientation and their learning strategies, which is outlined above. The authors thus confirm that highly-motivated students tend to employ diverse learning strategies to improve their English learning efficiency. Besides, the study also proves that students forced to learn English tend to perform badly in learning strategies selecting, for the correlation coefficients between extrinsic goal and learning strategies rank quite low in scale. Self efficacy, on the contrary, is proved to be closely correlated with learning strategies, which means confident students tend to employ learning strategies more frequently and effectively.

In addition, the validity of Self Access English Learning System is inspected by employing Regression analysis of SPSS, in which scores from 100 students in general are used to get regression equation and then the comparison of predicted scores by equation and real score is made. The comparison, however, shows that Self Access English Learning System is valid to what extent the predicted scores have no difference with students' real score. In addition to the comparison, the validity of regression equation, at the same time, proves the possibility that the students' future performance can be predicted, because no difference exists between predicted score and their real final examination scores.

There are also a number of implications for system users and performers with respect to pedagogical insights. The data presented in this paper provide reasonable evidence for the benefits of self-determination. College students' motivation is positively affected by the experience of autonomy. The college students here who perceived their instructors to be supportive of autonomy by allowing students to participate in course policy-making, report greater levels of motivation at the end of the semester, even after partialling out the effects of pretest motivation. Perceptions of autonomy have positive effects not only on intrinsic motivation, but also upon task value and self-efficacy.

As a whole, the pattern of results reported here indicates that experiences of classroom autonomy in the college classroom are more closely related to motivational factors than to performance. While the immediate experience of autonomy may not be directly facilitative of high course grades, autonomy does seem to modestly foster intrinsic goal orientation, task value, and self efficacy, all of which are critical components of continuing motivations. By promoting learning autonomy and self-determination in the college classroom, instructors may not see clear, immediate improvements in performance. Instead, students tend to select more additional courses related to English learning, accumulate more interests in the English learning materials provided by instructors, and show greater persistence facing difficulties in English learning. These are not insubstantial consequences, and we should not neglect factors that promote these positive motivational beliefs in a single-minded search for factors related to higher grades and better performance.

\section{CONCLuSION}

In this study, the social cognitive approach is employed to the research of learning motivations and learning strategies as the theoretical framework to explore the inner relationship between motivation orientations and learning strategies. Altogether 540 pieces of questionnaire were distributed to non-English majored students in Dalian University of Technology who learnt English in a blended environment. 
Using the software SPSS, the data were thoroughly analyzed, indicating that students who display more adaptive self-regulatory strategies demonstrate better learning efficacy and higher motivation for learning and students' performance is predictable with the help of learning motivation and strategies. Therefore, conclusions may be drawn that various kinds of learning strategies should be introduced and explained in English teaching and learning according to students' different learning motivations, thus narrowing the gap of students' English learning efficacy in blended learning environment.

\section{ACKNOWLEDGMENT}

The current study is part of the research projects "Study on Models of Innovative Foreign Language Talents Education" and "Study and Practice on Models of Graduate English Learning in Blended Environment", sponsored by Liaoning Social Science Funds (2009, L09DYY012) and Dalian University of Technology's Graduate Teaching Reform and Research Projects (2010, JG1057).

\section{REFERENCES}

[1] Bersin, J., \& Howard, C. (2004). Blended Learning: What Works? Retrieved from https://equinox.ntu.edu.sg/index.php?option=com_content\&task=view\&id=229\&Itemid=123 (accessed 16/12/2011).

[2] Driscoll, M. (2002). Blending learning: Let's get beyond the hype. Retrieved from http://www-07.ibm.com/services/pdf/blended_learning.pdf (accessed 16/12/2011).

[3] Gardner, R., \& Lambert, W. E. (1972). Attitude and Motivation in Second Language Learning. Rowley, MA: Newbury House.

[4] Gardner, R. (1985). Social Psychology and Second Language Learning. London: Edward Arnold.

[5] Garrison, D. R., \& Kanuka, H. (2004). Blended learning: Uncovering its transformative potential in higher education. The Internet and Higher Education, 7 (2): 95-105.

[6] Graham, C. R. (2005). Blended learning systems: Definition, current trends, and future directions. Handbook of blended learning: Global perspectives, local designs. San Francisco, CA: Pfeiffer.

[7] Harriman, G. (2004). What is Blended Learning? Retrieved from http://www.grayharriman.com/blended_learning.htm (accessed 16/12/2011).

[8] Liu, W. Y. \& Cha, J. (2009). Motivation Orientation in a Web-Based Environment. Foreign Languages Research, 3: 121-123.

[9] Liu, W. Y. \& Cha, J. (2010). English Learning Motivation and Strategy Study in a Web-Based Environment. Foreign Languages Research, 3: 46-51.

[10] Nota, L., Soresi, S., \& Zimmerman, B. J. (2004). Self-regulation and academic achievement and resilience: A longitudinal study. International Journal of Educational Research, 198-215.

[11] O' Malley, J. M., \& Chamot, A. U. (1990). Learning Strategies in Second Language Acquisition. Cambridge University Press.

[12] O' Malley et al. (1985). Learning Strategies Used by Beginning and Intermediate ESL Students. Language Learning, 35: 21-46.

[13] Pintrich, P. R., \& De Groot, E. (1990). Motivational and self-regulated learning components of classroom academic performance. Journal of Educational Psychology, 82: 33-40.

[14] Pintrich, P. R. (2000). Multiple goals, multiple pathways: The role of goal orientation in learning and Achievement. Journal of Educational Psychology, 92, 544-555.

[15] Pintrich, P. R. (2003). A motivational science perspective on the role of student motivation in learning and teaching contexts. Journal of Educational Psychology, 95: 667-686.

[16] Pintrich, P., \& Zushoa, A. (2002). Development of Achievement Motivation. Academic Press.

[17] Singh, H. (2003). Building Effective Blended Learning Programs. Educational Technology, 51-54.

[18] Valentine, J.C., DuBois, D.L., \& Cooper, H. (2004). The relations between self-beliefs and academic achievement: A meta-analytic review. Educational Psychologist, 39, 111-133.

[19] Weinstein, C. E., \& Mayer, R. E. (1986). The teaching of learning strategies. In Handbook of research on teaching. New York: Macmillan.

[20] Zimmerman, B. J., \& Schunk, D. H. (2001). Self-regulated learning and academic achievement: Theoretical perspectives. Mahwah, NJ: Lawrence Erlbaum Associates.

Wenyu Liu received his Ph.D. from Dalian University of Technology and now is a Professor in the School of Foreign Languages at Dalian University of Technology. He has been teaching since 1993. From 2009 to 2010, he worked at the University of Minnes ota Twin cities, the U.S.A. as a Fulbright research scholar. His research interests are teaching English as a second or foreign language, computer assisted language learning and neurolinguistics.

Hanjing Yu is now studying in Dalian University of Technology as a master candidate. Her research interests are ESL learning strategy and computer assisted language learning. 